\title{
Murgul-Akasya Ağaçlandırmalarının Yüzeysel Akış ve Sediment Taşınmasını Önlemedeki Etkileri ve Bunun Su Yönetimi-Kuraklık İlişkileri Bakımından İrdelenmesi
}

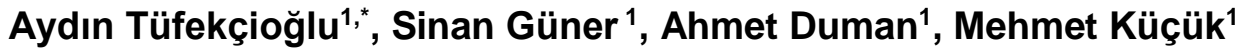 \\ ${ }^{1}$ Artvin Çoruh Üniversitesi, Orman Fakültesi, Orman Mühendisliği Bölümü, 08100, Seyitler, Artvin. \\ Özet
}

Yüzeysel akışın ve sediment taşınmasının uygun bitki örtüsü seçimi ile azaltılması ve yağan yağışların önemli bir kısmının infiltrasyonla toprağa girmesi ve toprakta depolanması kuraklı̆̆ı bitki gelişimi üzerinde yapacă̆ı olumsuz etkiye karşı bitkiyi daha dirençli kılacak, bitki büyümesinde görülen azalma ve kuruma gibi olumsuzlukları önemli ölçüde azaltacaktır. Ayrıca, bunun taşkın ve sellerin sebep olacağ zararları da azaltıcı etkisi olacaktır. Bu çalışmada, Artvin-Murgul yöresinde asit zararına maruz kalmış sahalarda yapılan yalancı akasya ăgaçlandırmalarının yüzeysel akış ve sediment taşınmasını önlemedeki etkileri hemen bitişiğindeki otlak alanları ile karșılaștırmak suretiyle araștırılmıștır. En fazla yüzeysel akıș ve sediment tașınımı Mayıs-Haziran ve Ekim-Kasım dönemlerinde olmuştur. Mayls-Kasım dönemindeki toplam yüzeysel aklş miktarı otlak alanında $263 \mathrm{~m}^{3} / \mathrm{ha}$ iken hemen bitişiğindeki orman alanında $18 \mathrm{~m} 3 / \mathrm{ha}$ olarak ölçülmüștür. Mayıs-Kasım dönemindeki toplam taşınan sediment miktarı otlak alanda 43,6 kg/ha iken, akasyalık alanda $5 \mathrm{~kg} / \mathrm{ha}$ olmuştur. Elde olunan sonuçlar akasya ağaçlandırmasının erozyonu ve yüzeysel akışı önlemede çayır alanlarına göre çok daha etkili olduğunu göstermektedir.

$\underline{\text { Anahtar Sözcükler }}$

Yüzeysel Akış, Erozyon, Yalancı Akasya, Murgul

\section{Influences of Black Locust Afforestation Studies in Murgul on Preventing Surface Runoff and Sediment Load and Examination of Results in Terms of Water Management and Drought Relations}

\begin{abstract}
Adverse effect of drought will be decreased with the selection of appropriate plant cover that cause reduction in surface runoff and soil erosion and increase in water availability through increased infiltration. This will also help plant growth and resistance to drought. In addition, plant cover will decrease damage from flooding and land sliding. In this study, effects of black locust afforestation studies in acid rain influenced areas on surface runoff and sediment transportation were investigated and compared to adjacent grasslands. The highest surface runoff and sediment transportation were measured in the periods of May-June and October-November. The total surface runoff in grassland area was $263 \mathrm{~m}^{3} / \mathrm{ha}$ while it was $18 \mathrm{~m}^{3} / \mathrm{ha}$ in adjacent black locust area between May and November. The total amount of sediment transported in the same period were $43.6 \mathrm{~kg} / \mathrm{ha}$ in grassland and $5 \mathrm{~kg} / \mathrm{ha}$ in black locust area, respectively. Our results indicate that the black locust afforestation studies were more effective than grasslands in preventing erosion and surface runoff in the region.
\end{abstract}

Keywords

Surface Runoff, Erosion, Black Locust, Murgul

\section{Giriş}

Yüzeysel akış, erozyonla taşınan sediment miktarını, havzaların su verimini, toprakta depolanan su miktarını, taşkın ve sellerin oluşmasını doğrudan etkileyen, hidrolojik döngünün önemli bileşenlerinden biridir. Bir alandaki yüzeysel akış, yağış şiddeti, arazi şekli, toprak özellikleri ve bitki örtüsü özellikleri gibi etmenler tarafından kontrol edilmektedir. Amerika Birleşik Devletleri'nde yapılan bir çalışmada değişik işleme şekillerine maruz mısır tarlalarında yıllık yüzeysel akış miktarı 1190 ile $2450 \mathrm{~m} 3 /$ ha arasında değişmiştir (Wendt ve Burwell 1985). Aynı alanlarda taşınan yıllık sediment miktarı 0.6 ile 22 ton/ha arasında ölçülmüştür.

Balcı (1958), Elmalı Barajı yağış havzasında yaptığı çalışmada, toplam yıllık yağışın orman, çayır ve çıplak alanda sırasıyla \%18, 36 ve 56’lık kısmının yüzeysel akışla uzaklaştığını belirlemiştir. İlgi çalışmadaki toplam yıllık yüzeysel akış miktarları orman, çayır ve çıplak alanda sırasıyla 2410, 4810 ve $7440 \mathrm{~m} 3 /$ ha olarak belirlenmiştir. Zengin (1997), 
İzmit yöresinde sahil çamı, radiata çamı, karaçam ve yapraklı türlerden oluşan baltalık meşçerelerinde yaptığı hidrolojik araştırmalarda, yıllık yüzeysel akış miktarlarını sırasıyla 52, 105, 102 ve $124 \mathrm{~m} 3 /$ ha olarak belirlemiş̧tir.

Özhan (1982), yıllık 1095,6 mm yağış alan İstanbul Belgrad Ormanındaki meşe, baltalık ve karaçam meşcerelerinde yaptı̆̆ı çalışmada, yıllık intersepsiyon miktarını meşe için $171,3 \mathrm{~mm}$, baltalık için $151.4 \mathrm{~mm}$, karaçam için ise 310.2 $\mathrm{mm}$ olarak bulmuş; yıllık yüzeysel akış miktarını meşe için $438 \mathrm{~m} 3 / \mathrm{ha}$, baltalık için $526 \mathrm{~m} 3 / \mathrm{ha}$, karaçam için ise 328 $\mathrm{m} 3$ /ha olarak ölçmüş̧; yıllık toplam buharlaşma miktarını ise meşe için $944.7 \mathrm{~mm}$, baltalık için $872,2 \mathrm{~mm}$, karaçam için ise $985,7 \mathrm{~mm}$ olarak belirlemiştir. Şu haliyle, yıllık yă̆gșı $400 \mathrm{~mm}$ civarında olan Ankara gibi illerimizde karaçam dikerek orman olmasını beklemek pek mümkün görünmemektedir. Çünkü İstanbul koşullarında bir karaçam meşceresinin sadece intersepsiyon ile kaybettiği su 310 mm'dir. Aynı koşullarda meşe yapraklı ormanın kaybettiği su ise 170 mm'dir.

Mevki faktörlerinden eğim, arazi kullanım biçimi ile değişmekle birlikte, yüzeysel akış üzerinde önemli etkiye sahiptir. Aydemir (1973), Bolu yöresinde farklı eğimdeki değişik arazi kullanım biçimlerinde yaptı̆̆ yüzeysel akış çalışmasında, yüzeysel akış miktarının arazi eğimi ile önemli ölçüde arttı̆̆ını saptamıştır. İlgi çalışmada, \% 15 eğimdeki farklı arazi kullanım biçimlerinde yıllık yüzeysel akış miktarları mısır tarlası için $3176 \mathrm{~m} 3 / \mathrm{ha}$, buğday tarlası için 3127 $\mathrm{m} 3 / \mathrm{ha}$, nadas alanı için $3854 \mathrm{~m} 3 / \mathrm{ha}$, findıklık için $1157 \mathrm{~m} 3 / \mathrm{ha}$ ve orman alanı için ise $61 \mathrm{~m} 3 / \mathrm{ha}$ olarak belirlenmiştir. Aynı çalışmada \% 45 eğimdeki parsellerdeki yıllık yüzeysel akış miktarları ise, mısır tarlası için $4863 \mathrm{~m} 3$ /ha, buğday tarlası için $4846 \mathrm{~m} 3 / \mathrm{ha}$, nadas alanı için $5432 \mathrm{~m} 3 / \mathrm{ha}$, findıklık için $1726 \mathrm{~m} 3 /$ ha ve orman alanı için ise $151 \mathrm{~m} 3 / \mathrm{ha}$ olarak belirlenmiştir. Yıllık ortalama yağışın $1128 \mathrm{~mm}$ olduğu çalışma sahasında, ortalama olarak toplam yağışın mısır tarlasında $\% 35$ 'i, buğday tarlasında $\% 34,5$ 'i, nadas alanında $\%$ 40,1'i, findıklıkta $\% 15,3$ 'ü ve orman alanında $\% 1,6$ 's1 yüzeysel akışla parsellerden uzaklaşmıştır. İlgi çalışmada, taşınan yıllık sediment miktarları ise \% 15 eğimdeki parsellerde, mısır tarlasında 6976 ton/ha, buğday tarlasında 5560 ton/ha, nadas alanında 6778 ton/ha, findıklıkta 1321 ton/ha ve orman alanında ise ölçülemeyecek kadar azdır. Aynı çalışmada \% 45 eğimdeki parsellerde ölçülen yıllık taşınan sediment miktarları ise mısır tarlasında 12546 ton/ha, buğday tarlasında 10184 ton/ha, nadas alanında 10357 ton/ha, findıklıkta 3357 ton/ha, orman alanında ise ölçülemeyecek kadar azdır.

Yüzeysel akış miktarı toprakta depolanan su ve nehirlere ulaşan su üzerinde doğrudan etkili olduğu için, gerek taşkınların önlenmesi ve gerekse bitki gelişimi-kuraklık ilişkileri konularında önem arz etmektedir. Ancak, Ülkemizin Doğu Karadeniz bölümünde bu konuda yapılmış herhangi bir çalışma bulunmamaktadır. Bölgenin sahil kesimi sık sık sel felaketlerine maruz kalmakta, Karadeniz ardı kesimi ise belli aralıklarla oluşan kuraklıklardan etkilenmektedir.

Yalancı akasya (Robinia pseudo-acacia L.), gençlikte hızlı büyümesi, kökleri ile havanın serbest azotunu bağlayabilmesi, kuraklığa dayanıklı olması, fakir yetişme ortamlarında gelişebilmesi, odununun çürümeye karşı dayanıklı olması, iyi yanması ve 1sı değerinin yüksek olması, yapraklarının hayvanlar tarafından sevilerek yenmesi, çiçeklerinin arılar tarafindan tercih edilmesi gibi özellikleri nedeniyle özellikle son yıllarda toprağı sslah etme ve erozyonu önleme gibi amaçlar ile ağaçlandırmalarda en çok kullanılan türlerden biridir. Yalancı akasyanın gençlikte hızlı büyümesi, onu özellikle karbon depolama, yakacak-yapacak odun üretimi ve biyoenerji üretimi bakımından oldukça önemli kılmaktadır. Bu konu, küresel ısınmanın her gün biraz daha kendini hissettirdiği dünyamızda, üzerinde önemle durulması gereken hususlardan birini teşkil etmektedir. Fosil yakıtların gelecekte tükeneceği göz önünde bulundurulursa, yalancı akasya ile oluşturulabilecek biyoenerji ormanlarının değeri çok daha iyi anlaşılabilecektir. Tarafımızdan Gümüşhane-Torul'da yapılan ön çalışmada, yalancı akasyanın dikimden 8 yıl sonra, hektarda yaklaşık 7 ton karbon kazanımı sağladığı belirlenmiştir (Tüfekçioğlu vd. 2002). Bu değer yaklaşık olarak bir arabanın tüm ömrü boyunca havaya yaydığı karbona ( 8.3 ton) (Çepel 2003) eşdeğerdir. Artvin'de yaklaşık 40.000 ha'lık ağaçlandırmaya söz konusu alan olduğu ve bu alanların büyük çoğunluğunun yalancı akasya ağaçlandırmasına uygun olduğu Artvin İl Çevre Orman Müdürlüğü Ağaçlandırma Şube Müdürlüğü tarafindan bildirilmektedir.

$\mathrm{Bu}$ çalışmada, Artvin-Murgul yöresinde asit zararına maruz kalmış sahalarda yapılan yalancı akasya ağaçlandırmalarının yüzeysel akış ve sediment taşınmasını önlemedeki etkileri hemen bitişiğindeki otlak alanları ile karşılaştırmak suretiyle araştırılmıştır.

\section{Materyal ve Yöntem}

Çalışmaya konu olan yalancı akasya ağaçlandırmaları, 1996 yılında, Artvin Orman Bölge Müdürlüğü'ne bağlı Murgul Orman İşletme Müdürlüğü tarafından ağaçlandırma yapılan dört alanı kapsamaktadır (Orman Genel Müdürlüğü bünyesinde gerçekleştirilen yeniden yapılanma çalışmaları sonucunda, 2003 yılında Murgul Orman İ̧̧letme Müdürlüğü kapatılarak, Borçka Orman İşletme Müdürlügü’ne katılmıştır). Deneme alanları yaklaşık 600 metre yükseltide, kuzey ve güneybatı bakılarda ve ortalama eğimi \% 30-50 arasında değişen sahalarda kurulmuştur. Bu amaçla, 6 adet yüzeysel akış parseli akasya sahasında ve 6 adet de bitişiğindeki yoğun otlatmaya maruz kalmış otlak alanlarında alınmıştır. Yüzeysel akış parsellerinin uzunluğu $4 \mathrm{~m}$, genişliği $1,5 \mathrm{~m}$ ve toplam büyüklüğü ise $6,9 \mathrm{~m} 2$ olarak alınmıştır. Parsellerin kenarları $20 \mathrm{~cm}$ genişliğinde, $2 \mathrm{~mm}$ kalınlığında paslanmaz saclarla sınırlanmıştır. Sacların alt kısmı $10 \mathrm{~cm}$ toprağa gömülmüsşür. Parsellerin alt ucunda saclar "V" şeklinde toprağa çakılarak ortalarına çinko oluklar yerleştirilmiştir. Çinko olukları sabitleştirmek için altlarına ve yanlarına bir miktar çimento harcı koyulmuştur. Toplama kabı olarak 50 lt'lik plastik kovalar kullanılmıştır. Örnek toplama ve kovaların boşaltılması her şiddetli yağıştan sonra gerçekleştirilmiştir. Toplanılan örnekler üzerinde sediment miktarı tayini, süzgeç kağıdı üzerinden numunelerin süzülmesi ve daha sonra 24 saat $105^{\circ} \mathrm{C}$ de kurutularak tartılması suretiyle yapılmıştır. 


\section{Bulgular ve Tartışma}

Akasyalık ve çayırlık alanlardaki toplam yüzeysel akış ve taşınan sediment miktarlarının Mayıs-Kasım 2007 dönemindeki değişimi Şekil 1 ve 2'de görülmektedir. En fazla yüzeysel akış ve sediment taşınımı Mayıs-Haziran ve Ekim-Kasım dönemlerinde olmuştur. Mayıs-Kasım dönemindeki toplam yüzeysel akış miktarı otlak alanında 263 $\mathrm{m} 3 /$ ha iken hemen bitişiğindeki orman alanında $18 \mathrm{~m} 3 /$ ha olarak ölçülmüştür. Mayıs-Kasım dönemindeki toplam taşınan sediment miktarı otlak alanda $43,6 \mathrm{~kg} / \mathrm{ha}$ iken, akasyalık alanda $5 \mathrm{~kg} / \mathrm{ha}$ olmuştur. Elde olunan sonuçlar akasya ağaçlandırmasının erozyonu ve yüzeysel akışı önlemede çayır alanlarına göre çok daha etkili olduğunu göstermektedir. Benzer sonuçlar Balcı (1958) tarafından Elmalı barajı sahasındaki çayır ve orman alanlarında da gözlemlenmiştir. Buğday tarlası, nadas alanı, mısır tarlası ve ormanı taşınan sediment miktarı bakımından karşılaştıran Aydemir (1973); misır tarlasında 12546 ton/ha, buğday tarlasında 10184 ton/ha, nadas alanında 10357 ton/ha, findıklıkta 3357 ton/ha, orman alanında ise ölçülemeyecek kadar az sediment miktarı belirlemiştir. Bizim bulduğumuz yüzeysel akış ve taşınan sediment miktarı verilerinin daha düşük olmasında, verilerin sadece 7 aylık döneme ait olması ve bölgenin, diğer bölgelere göre nispeten daha yağışlı ve nemli olmasından kaynaklanmaktadır.

Bu çalışmada, otlak alanlarındaki yüzeysel akış ve taşınan sediment miktarının, akasya alanlarına göre daha yüksek olması, önemli ölçüde otlak alanlarında mevcut olan yoğun otlatmanın bir sonucudur. Otlatma ile üst toprak sıkışmakta ve ölü örtü ile toprağa organik madde girişi azalmaktadır. Ayrıca yağan yağış taneleri direk toprağa çarparak toprak yüzeyindeki gözeneklerin belli bir süre sonra tıkanmasına neden olmaktadır.

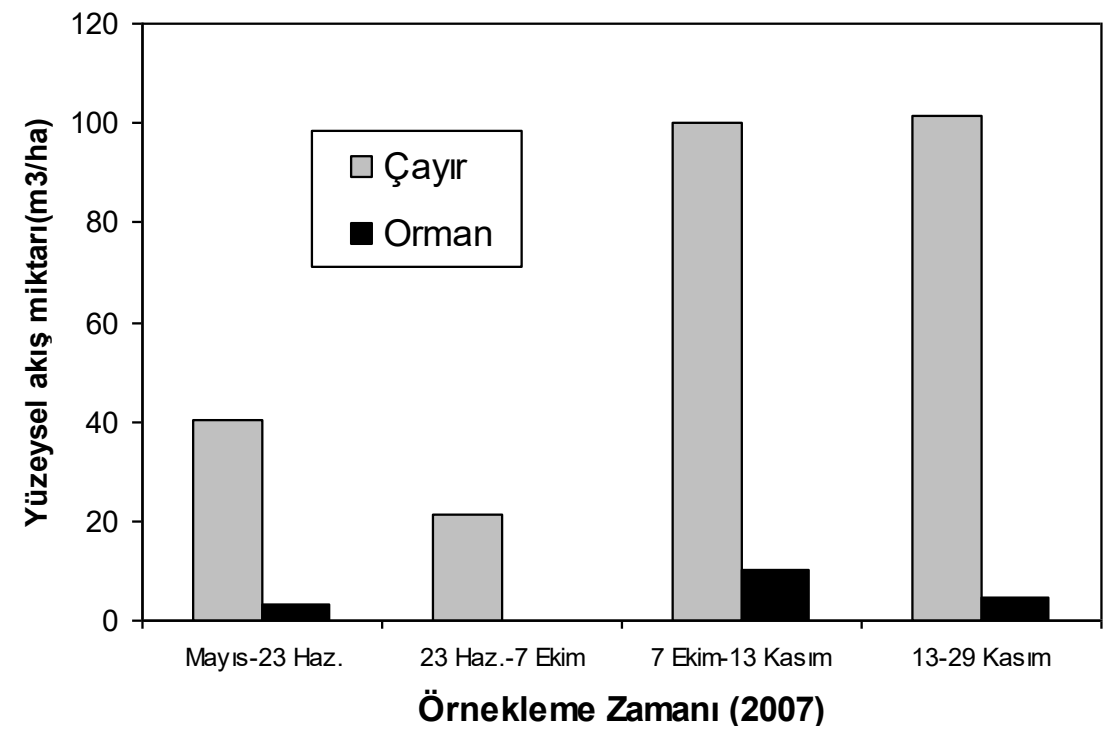

Şekil 1: Otlak ve akasya sahasında Mayıs-Kasım dönemleri arasında yüzeysel akış miktarları

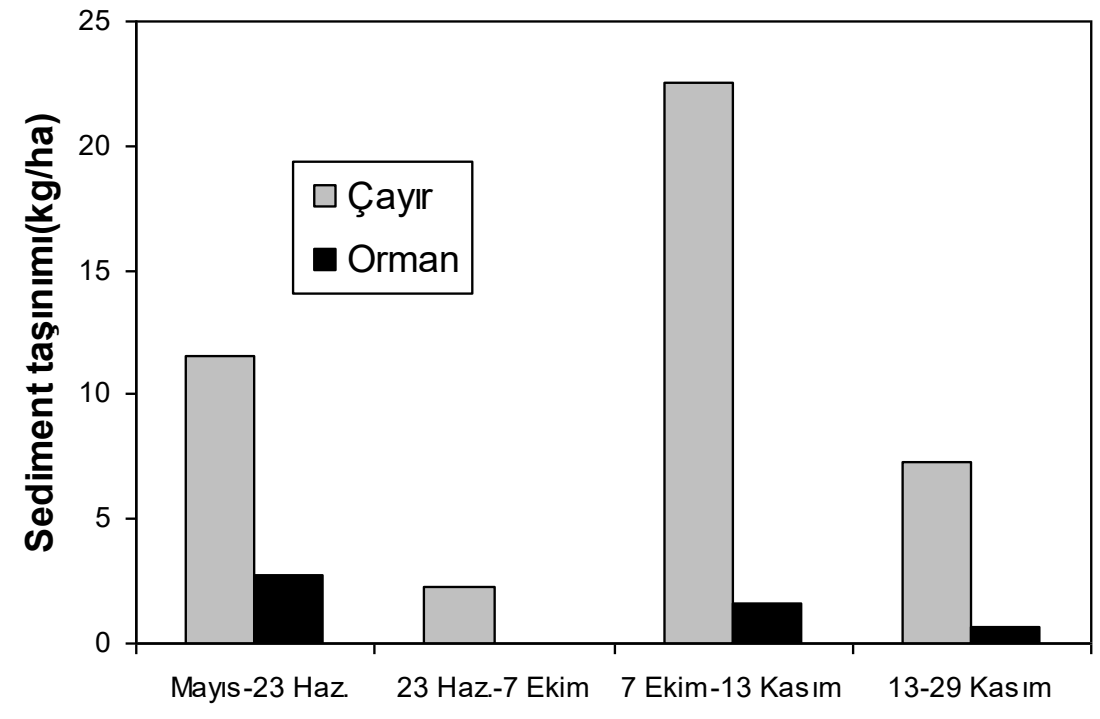

Örnekleme Zamanı (2007)

Şekil 2: Otlak ve akasya sahasında Mayıs-Kasım dönemleri arasında yüzeysel akışla taşınan sediment miktarları 


\section{Elde Edilen Sonuçların Su Yönetimi-Kuraklık İlişkileri Bakımından İrdelenmesi}

Kuraklık, orman ekosistemlerinin yaşamsal faaliyetleri üzerinde önemli olumsuz etkileri olabilen bir çevresel faktördür. Kuraklık oluşumu son yıllarda artan küresel sıcaklıklar ile artmış ve gelecekte daha da artması muhtemel görülmektedir. Kuraklık, havzaların su verimini düşürdüğü gibi, bitkilerinde toprak üstü artımını \% 30-70 oranında düşürebilmekte ve uzun dönemli olduğunda ise doğal yayılışlarını sınırlayabilmektedir (Çepel 1989). Ağaçların büyümesi \% 80-90 oranında suyun elverişliliği tarafından kontrol edilmektedir (Zahner 1968).

Kuraklığın bitki ekosistemleri üzerinde yaptığı olumsuz etkiyi azaltmanın yollarından biri de, ekosistemlerde olan yüzeysel akış ve sediment taşınmasının uygun bitki örtüsü seçimi ile azaltılmasıdır. Yağan yağışların önemli bir kısmının infiltrasyonla toprağa girmesi ve toprakta depolanması kuraklığın bitki gelişimi üzerinde yapacağı olumsuz etkiye karşı bitkiyi daha dirençli kılacak, bitki büyümesinde görülen azalma ve kuruma gibi olumsuzlukları önemli ölçüde azaltacaktır. Ayrıca, bu durum taşkın ve sellerin sebep olacağı zararları da azaltıcı yönde etki edecektir. Bu yönü ile Artvin-Murgul akasya alanları, otlak alanlarına göre, daha az yüzeysel akış ve sediment taşınmasına sahip oldukları için kuraklıktan etkilenme riskleri daha az görünmektedir. Ancak, akasya ağaçlarının transpirasyonla kaybedeceği suyun otlak alanlarına göre daha fazla olması bu riski artıııı yönde etki edecektir. Fakat ağaç türlerinin derin kök geliştirmeleri ile toprak kesitinin daha derinlerindeki suyu kullanabilmeleri sayesinde, kuraklığa daha dirençli olabilmektedirler. Savan alanlarında yaptıkları çalışmada, Baldocchi vd. (2004), topraktaki su potansiyelinin -2 MPa'a düştüğünde çayırların kuruyarak transpirasyon yapmadıklarını, buna karşılık meşe ormanında ağaçların -4 MPa'da bile düşük oranda transpirasyon yaptıklarını belirlemişlerdir.

Yöresel koşullara göre değişmekle birlikte, ormanlık alanlardan olan toplam buharlaşmanın, çayırlık alanlara göre fazla olması, kuraklığın etkilerini nispeten azaltıı yönde etkili olabilmektedir. Şöyleki; küresel ölçekteki evapotranspirasyonun sadece \% 15-20'lik bölümü karalardan gerçekleşmesine rağmen (Spiedel ve Agnew 1982; Westall ve Stumm 1980), karalara düşen yağışların sadece \% 10'luk kısmı denizlerden buharlaşan suyun yoğunlaşması ile oluşmaktadır (Perry 1994). Küresel düzeyde karalara düşen yağışların yaklaşık \% 65'i başka bir kara parçasından buharlaşan sudan kaynaklanmaktadır (Perry 1994). Panama, Malezya, Hindistan ve Filipinler'de ormanların tahrip edilerek tarım ve otlak alanlarına dönüştürüldüğü yörelerde, yirminci yüzyılda yağışlarda azalmalar belirlenmiştir (Meyers 1988; Windsor vd. 1986). Dolayısı ile ormanlardan atmosfere daha fazla su buharının verilmesi, karalara daha fazla yağış düşmesi olasılığını artıracaktır.

Gelecekte olası küresel 1sınma kaynaklı kuraklıklarda, havada artan CO2 konsantrasyonu sonucu stoma açılması daha az olacağından ormanlardan transpirasyonla olan su kaybı, otlak alanlarına göre daha fazla azalacaktır. Ancak, bu azalmanın artan sıcaklıklar sonucu yükselen transpirasyon miktarından fazla veya az olması konusu hala cevaplanması gereken önemli bir soru olarak beklemektedir.

Ağaç türü de havzanın yüzeysel akış ve su verimini önemli ölçüde etkileyen etmenlerden biridir. Avusturalya'da, ökaliptus ormanından radiata ormanına dönüştürülen alanlarda dere akımlarında ilk yıllarda 300 mm'ye varan artışlar saptanmıştır (Bren ve Hopmans 2007). Bu artış zamanla azalmış ancak radiata çamı ormanından, ökaliptus ormanına kıyasla daima evapotranspirasyonla daha az su kaybı olmuştur. Yine ABD'de ormanların kesildiği ve gelen vejetasyonun herbisitlerle kontrol edildiği havzalarda 350 mm'ye varan su verimi artışları belirlenmiştir (Hornbeck vd. 1993).

Havzaların ağaçlandırılması havzanın su verimini azaltıcı yönde etki etmektedir. Bu durum şehir şebeke sularının geldiği havzalarda önemle göz önünde bulundurulması gereken bir husustur. Ancak, ormanların dere akımlarını düzenleme fonksiyonları en az bu su verimi kadar önemli bir husustur. Ormanlar yüzeysel akışı azaltarak sel ve taşkınların oluşması riskini azaltmakta, erozyonu azaltarak baraj göllerinin dolmasını engellemekte ve su kalitesini artırmaktadırlar. Yazın sis yağışlarının olduğu alanlarda orman alanları, otlak alanlarına göre daha çok su verimine sahip olmaktadırlar (Bosch ve Hewlett 1982). Benzer şekilde yine yaşlı ormanlar, tıraşlama alanlarında oluşmuş genç ormanlara göre daha az su tüketerek havza su verimini artırabilmektedirler (Calder 1998).

\section{Kaynaklar}

Aydemir H., (1973), Bolu Masifinde Araziden Faydalanma Biçimlerinde Yüzeysel Akışla Su Kaybı ve Toprak Taşınması Üzerine Araştırmalar, Ormancılık Araştırma Enstitüsü, Teknik Bülten Serisi, Cilt 54, Cihan Matbaas1, Ankara.

Balcı A.N., (1958), Elmalı Barajının siltasyondan korunması imkanları ve vejetasyon su düzeni üzerine araştırmalar, Doktora Tezi, İstanbul Üniversitesi, İstanbul.

Baldocchi D.D., Xu L., Kiang N., (2004), How plant functional-type, weather, seasonal drought, and soil physical properties alter water and energy fluxes of an oak-grass savanna and an annual grassland, Agricultural and Forest Meteorology, 123, 13-19.

Bosch J.M., Hewlett J.D., (1982), A review of catchment experiments to determine the effect of vegetation changes on water yield and evapotranspiration, Journal of Hydrology, 55(1-4), 3-23.

Bren L., Hopmans P., (2007), Paired catchments observations on the water yield of mature eucalypt and immature radiata pine plantations in Victoria, Journal of Hydrology, 336(3-4), 416-429.

Calder I.R., (1998), Water-resource and land use issues, Water-Resource and Land-Use Issues, SWIM Paper 3, System-Wide Initiative on Water Management, Colombo, Sri Lanka.

Çepel N., (2003), Ekolojik sorunlar ve çözümleri, TÜBİTAK Yayınları, Ankara.

Çepel N., (1989), Orman Ekolojisi, İstanbul Üniversitesi Orman Fakültesi Yayınları, Yayın No: 3140-337, İstanbul. 
Hornbeck J.W., Adams M.B., Corbett E.S., Verry E.S., Lynch J.A., (1993), Long-term impacts of forest treatments on water yield: a summary for northeastern USA, Journal of Hydrology, 150(2-4), 323-344.

Meyers N., (1988), Tropical deforestation and climate change, Environmental Conservation, 15(4), 293-298.

Özhan S., (1982), Belgrad ormanındaki bazı meşcerelerde evapotranspirasyonun deneysel olarak saptanması ve sonuçların ampirik modellerle karşılaştırılması, İstanbul Üniversitesi Orman Fakültesi Yayınları, Yayın No: 311, İstanbul.

Perry D.A., (1994), Forest Ecosystems, The Jhon Hopkins University Press, U.S.A.

Spiedel D.H., Agnew A.F., (1982), The natural geochemistry of our environment, Westview Press, Colo, U.S.A.

Tüfekçioğlu A., Yüksek T., Kalay H.Z., (2002), Gümüşhane İli Torul İlçesi Yalancı Akasya Ağaçlandırmalarının Biyokütle ve Bazı Toprak Özellikleri Yönünden İncelenmesi, Gümüşhane ve Yöresinin Kalkınması Sempozyumu, 23-25 Ekim, Gümüşhane.

Wendt R.C., Burwell R.E., (1985), Runoff and soil losses for conventional, reduced, and no-till corn, Journal of Soil and Water Conservation 40, 450-454.

Westall J., Stumm W., (1980), The hydrosphere, In: The Handbook Of Environmental Chemistry, (Hutzinger O., Ed.), Springer Verlag, Berlin, pp.17-49.

Windsor G.M., Rand A.S., Rand V.M., (1986), Variation in rainfall on Barrow Colorado Island, Report of the Smithsonian Tropical Research Institute, Balboa, Panama.

Zahner R., (1968), Water deficits and growth of trees, In: Water Deficits And Growth Of Trees, (Kozlowski T.T., Ed.), pp.191-254. Academic Press, New York.

Zengin M., (1997), Kocaeli yöresinde orman ekosistemlerinin hidrolojik ağaçlandırmalar yönünden karşılaştırılması, Kavak ve Hızlı Gelişen Tür Orman Ağaçları Araştırma Enstitüsü, Yayın No: 217, İzmit. 